\title{
Transpiration directly regulates the emissions of water-soluble short-chained OVOCs
}

\section{Rissanen, Kaisa}

2018-10

Rissanen , K , Hölttä , T \& Bäck , J 2018 , ' Transpiration directly regulates the emissions of water-soluble short-chained OVOCs ' , Plant, Cell and Environment , vol. 41 , no. 10 , pp. pÿ2288 2298 . https://doi.org/10.1111/pce.13318

http://hdl.handle.net/10138/279380

https://doi.org/10.1111/pce.13318

submittedVersion

Downloaded from Helda, University of Helsinki institutional repository.

This is an electronic reprint of the original article.

This reprint may differ from the original in pagination and typographic detail.

Please cite the original version. 
1 Transpiration directly regulates the emissions of water-soluble short-

2 chained OVOCs

3

4 Authors: Rissanen, K., Hölttä, T \& Bäck, J.

5 Institute: Institute for Atmospheric and Earth System Research / Forest Sciences, Faculty of Agriculture

6 and Forestry, University of Helsinki

7

8 Author for correspondence:

$9 \quad$ Kaisa Rissanen

10 Address: Institute for Atmospheric and Earth System Research / Forest Sciences, Faculty of Agriculture

11 and Forestry, University of Helsinki, P.O. Box 27, FIN-00014, Finland

12 Email: kaisa.rissanen@helsinki.fi

13

14 
15 Transpiration directly regulates the emissions of water-soluble short16 chained OVOCs

18 Abstract

20 Most plant-based emissions of volatile organic compounds (VOCs) are considered to be mainly

21 temperature dependent. However, certain oxygenated VOCs (OVOCs) have high water solubility and also

22 regulation of their emission by stomatal conductance has been suggested. However, due to their water

23 solubility and sources in stem and roots, transport in xylem sap has been suggested to play a role in their

24 shoot emissions. Yet, further understanding on this role has been lacking until present.

25 We used shoot-scale long-term dynamic flux data from Scots pine (Pinus sylvestris) trees to analyse the

26 effects of transpiration and transport in xylem sap flow on emissions of three water soluble OVOC:

27 methanol, acetone and acetaldehyde. We found a direct effect of transpiration on the shoot emissions of

28 the three OVOCs. The emissions were best explained by a regression model that combined linear

29 transpiration and exponential temperature effects. In addition, a structural equation model indicated that

30 stomatal conductance affects emissions mainly by regulating transpiration, and that a part of

31 temperature's effect is also indirect.

32 The tight coupling of shoot emissions to transpiration clearly evidences that these OVOCs are transported

33 in xylem sap from their sources in roots and stem to leaves and to ambient air.

34 Keyword index

35 Acetone, acetaldehyde, long-distance transport, methanol, OVOC emissions, temperature, transpiration, $36 \quad x y l e m$ sap 


\section{Introduction}

41 Plant produced volatile organic compounds (VOCs) are an important factor in the troposphere. They

42 contribute to ozone formation and destruction, as well as to the formation and growth of new

43 atmospheric particles. The production and emissions of plant emitted VOCs have been extensively

44 studied and modelled to explain and predict these atmospheric processes better. The emission models,

45 for example for terpenoids, are mainly based on temperature and/or light (Guenther et al., 1993;

46 Guenther 1995; Guenther 1995, Simpson et al., 1995). Other physiological controlling factors have been

47 rarely used in the models. However, the emission dynamics of water-soluble compounds (Henry's law

48 coefficient $(H)$ under $100 \mathrm{~Pa} \mathrm{~m}^{3} \mathrm{~mol}^{-1}$ at $25^{\circ} \mathrm{C}$ ), such as short-chained oxygenated VOCs (OVOCs), depend

49 also on the dynamics of water phase inside the plant. This dependence could play a central role in

50 regulating emissions and should not be ignored.

51 In contrast to the emissions of non-water-soluble compounds, the emissions of water-soluble OVOCs, such

52 as, methanol $\left(H=0.461 \mathrm{~Pa} \mathrm{~m}^{3} \mathrm{~mol}^{-1}\right.$ at $\left.25^{\circ} \mathrm{C}\right)$, acetone $\left(\mathrm{H}=3.88 \mathrm{~Pa} \mathrm{~m}^{3} \mathrm{~mol}^{-1}\right.$ at $\left.25^{\circ} \mathrm{C}\right)$ and acetaldehyde $(\mathrm{H}=$

$537.0 \mathrm{~Pa} \mathrm{~m}^{3} \mathrm{~mol}^{-1}$ at $25^{\circ} \mathrm{C}$ ) may be regulated by stomatal conductance (Niinemets et al., 2003, 2004; Harley

54 et al., 2007). When stomatal conductance decreases, increase in the partial pressure in sub-stomatal cavity

55 enhances the partitioning of the water-soluble compounds into water films. Thus, the partial pressure in

56 the sub-stomatal cavity increases less than for non-water soluble compounds, and the partial pressure

57 difference between sub-stomatal air and ambient air cannot necessarily overcome the stomatal limitation

58 of flux (Niinemets et al., 2003). This regulation is apparent, for example, when the stomata open in the

59 mornings. Low stomatal conductance in the nights enables the accumulation of water soluble compounds 
that are then released as the stomata open, creating the sudden morning bursts that can be detected in several plant species (Mac Donald et al., 1993; Nemeck-Marshall et al., 1995; Harley et al., 2007; Folkers et al., 2008; Saunier et al., 2017).

In addition to stomatal conductance, transpiration has been detected to correlate with emissions of water soluble compounds. Kreuzwieser et al., (2001), Cojocariu et al., (2004) and Filella et al., (2007) have reported a correlation between transpiration and acetaldehyde emissions. Acetaldehyde is produced from ethanol $\left(H=0.507 \mathrm{~Pa} \mathrm{~m}^{3} \mathrm{~mol}^{-1}\right.$ at $\left.25^{\circ} \mathrm{C}\right)$ that can be transported in the xylem (Kreuzwieser et al., 2000; Fall et al., 2003). Grabmer et al., (2008), Harley et al., (2007) and Folkers et al., (2008) have also reported links between methanol emissions and transpiration. This link has been explained by the fact that transpiration combines the impacts of temperature and stomatal conductance (Harley et al., 2007), or by possible methanol transport in xylem (Grabmer et al., 2006; Folkers et al., 2008). Cojocariu et al., (2004) observed a correlation between acetone emissions and transpiration, but had no further hypothesis on its origin. These findings suggest that also transpiration could play a role in regulating emissions of water-soluble compounds, for example, though the transport of the compound, or its precursor in case of acetaldehyde,

74 in xylem sap. In addition, although less water soluble than, for example, methanol, acetone and acetaldehyde, also $\mathrm{CO}_{2}\left(H=2937 \mathrm{~Pa} \mathrm{~m}^{3} \mathrm{~mol}^{-1}\right.$ at $\left.25^{\circ} \mathrm{C}\right)$ is known to travel long distances in the xylem sap (McGuire \& Teskey, 2004; Bowman et al., 2005; Bloemen et al., 2013).

The transport of $\mathrm{CO}_{2}$ in the xylem sap had been suggested as early as 1933 by Boysen-Jensen (BoysenJensen, 1933). Later in 2009, Hölttä and Kolari presented a detailed theoretical framework for $\mathrm{CO}_{2}$ transport in the xylem sap (Hölttä \& Kolari, 2009). Those authors found that a proportion of the $\mathrm{CO}_{2}$ produced by stem respiration dissolves in the xylem sap and is transported upwards. The remainder of the

$81 \mathrm{CO}_{2}$ diffuses through the bark into the atmosphere, and it is measured as stem respiration. Xylem sap

82 velocity should affect the stem $\mathrm{CO}_{2}$ emissions negatively in the lower parts of stems, where a large 83 proportion of the $\mathrm{CO}_{2}$ is captured by dissolution in the xylem sap due to a combination of low $\mathrm{CO}_{2}$ 
84 concentrations in the sap and the large diffusion resistances created by thick bark. Transported $\mathrm{CO}_{2}$ affects

85 the emissions positively in the top parts of stems, where bark is thinner and the water has become

86 saturated with $\mathrm{CO}_{2}$ due to stem tapering, and thus more $\mathrm{CO}_{2}$ diffuses into the ambient air (Hölttä \& Kolari

87 2009). The association between xylem sap velocity and $\mathrm{CO}_{2}$ emissions in shoots is theoretically positive,

88 but it cannot be directly measured, because photosynthesis consumes the $\mathrm{CO}_{2}$ (Bloemen et al., 2013). A

89 negative correlation between $\mathrm{CO}_{2}$ emissions from tree stem and xylem sap flux velocity has also been

90 reported by McGuire and Teskey (2004), Bowman et al., (2005), Gansert and Burgdorf (2005), McGuire et

91 al., (2007), among others. The difference between the dynamics in different stem parts is indicative of

92 stem $\mathrm{CO}_{2}$ fluxes that are higher in the upper compared to the lower stem (Hölttä \& Kolari, 2009). A similar

93 pattern could also be expected for OVOC emissions from stem (Fig. 1).

94 When analysing the role of transport in the emissions of water soluble compounds, it is important also to

95 consider their sources in the plants. The site of production determines the proportion of a compound that

can dissolve into the xylem sap and be transported to leaves in relation to the proportion that directly diffuses into the ambient air. Subsequently, it affects the role of transported compounds in total leaf emissions in relation to the compounds that are produced in leaves. Sources of methanol, acetone and acetaldehyde vary considerably in plants, but importantly, they are not confined to any single plant tissue (Seco et al., 2007). The largest methanol source is the demethylation of pectin during cell wall formation (Galbally \& Kristine, 2002; Hüve et al., 2007). It is thus produced in all growing tissues from the leaves to the root tips. Smaller methanol sources in plants originate from processes that are related to protein repair (Fall \& Benson, 1996; Seco et al., 2007) and to plant stresses, such as, herbivory or mechanical wounding (Fall, 2003; Peñuelas et al., 2005; Loreto et al., 2006). As mentioned earlier, one source of acetaldehyde is ethanol that is produced in roots especially under anaerobic conditions (Kreuzwieser et al., 1999, 2000; Fall et al., 2003), or in vascular cambium (MacDonald and Kimmerer, 1991). Another acetaldehyde source is the pyruvate overflow mechanism in leaves (pyruvic acid decarboxylation) during light-dark transitions 
108 (Karl et al., 2002; Fall, 2003; Hayward et al., 2004; Seco et al., 2007; Jardine et al., 2008). Acetone has many

109 different and separate sources in plants, but these are currently not well known or quantified. One

110 production pathway is possibly connected to the decarboxylation of the acetoacetates such as those that

111 occur in micro-organisms and in animals (Fall, 2003).

112 Although the transport hypothesis has been suggested earlier and it is somewhat established for

113 acetaldehyde, to the best of our knowledge this is the first attempt to address the roles of transpiration

114 and long-distance xylem transport in the emissions of especially methanol and acetone. We studied this

115 transport by using long-term field measurements that covered five annual growing seasons. Our approach

116 was to analyse and separate the effects of temperature, transpiration and stomatal conductance on

117 methanol, acetone and acetaldehyde emissions of Scots pine in uncontrolled field conditions._We

118 hypothesised that 1) methanol, acetone and acetaldehyde can be transported to the shoots in xylem sap

119 and 2) and that subsequently, the transpiration positively affects the emissions of methanol, acetone and

120 acetaldehyde from the shoots.

121 Materials and methods

122 The data were collected in southern Finland, at the SMEAR II (station for measuring ecosystem-

123 atmosphere interactions) site in Hyytiälä Forestry Field station. The site is an approximately 50-year-old

124 Scots pine (Pinus sylvestris L.) dominated forest, with smaller numbers of silver birch (Betula pendula

125 [Roth]), downy birch (Betula pubescens [Ehrh.], Norway spruce (Picea abies [L.] karst.) and European aspen

126 (Populus tremula). The soil is mainly podzolic with a shallow humus layer. More details on the stand are

127 found in the publications by llvesniemi et al., (2010) and Hari et al., (2013).

128 Exchange (fluxes) of OVOCs between the Scots pine (Pinus sylvestris) shoots and stems and atmosphere

129 were measured continuously using a dynamic enclosure system that is described in detail by Kolari et al., 130 (2012) and by Vanhatalo et al., (2015). The shoot scale emissions have been measured in a total of five 
131 pines and 21 shoots of different age classes since 2009. The data used in this study were obtained from 3

132 different Scots pines on the site, and 5 different shoots measured from May to August 2010, 2011, 2013,

1332014 and 2015. The 2012 data contained too many gaps due to instrument malfunctions, for example, to

134 be comparable to the other years studied. All the shoots contained only 1-year-old needles, as the new

135 buds had been removed before chamber installation. These buds were removed for two reasons: the first

136 reason was because the growing shoot would have become too big to fit in the chamber in late summer

137 and, the second reason was because our aim was to measure the emissions without the confounding large

138 effect that shoot and needle growth in spring and early summer would have on emissions (Aalto et al.,

139 2014). In addition, we used data from pine stem chambers that were attached to three heights above

140 ground on one pine stem (Vanhatalo et al., 2015). The lowest chamber was positioned at 7 metres, well

141 below the living canopy, where the stem diameter was $11.6 \mathrm{~cm}$. The middle chamber was installed at 12

142 metres, in the lower part of the living canopy, where the stem dia meter was $8.4 \mathrm{~cm}$. The top chamber was

143 placed at 16.5 metres, near the tree top, where the stem diameter was $3.5 \mathrm{~cm}$. The three chambers were

144 measured simultaneously throughout April 2013 and the middle chamber was measured through the

145 entire 2013 growing season.

146 The dynamic enclosure system consists of shoot and stem chambers that close cyclically, for 3 minutes at

147 a time. During the closure, sample air was drawn from the chamber into gas analysers. Small holes in the

148 chamber enabled ambient air to replace sample air flow. Some of the sample air drawn from chambers

149 was directed to a PTR-MS quadrupole (Photon transfer reaction - quadrupole mass spectrometer, lonicon

150 Analytik, Innsbruck, Austria), which was set to measure certain protonated masses, in this case, masses

$151 \mathrm{~m} / \mathrm{z} 33$ (methanol), $\mathrm{m} / \mathrm{z} 45$ (acetaldehyde) and m/z 59 (acetone). The shoot emissions were calculated for

152 the OVOC concentration increase in the chamber air during enclosure time by using mass-balance

153 equations as described by Hari et al., (1999) and by Kolari et al., (2012). Because ambient air was used as 
154 replacement air, the concentration inside the chamber at the beginning of the closure equalled the 155 concentration in the replacement air. In this case, we used the simplified equation (Eqn 1).

$$
C(t)=C_{0}+\frac{E}{F}\left(1-e^{-\frac{F t}{v}}\right)
$$

159 In Equation 2, $\mathrm{C}(\mathrm{t})$ is the concentration in the chamber as a function of time, $\mathrm{C}_{0}$ is the concentration in the 160 chamber at the beginning of the measurement, $v$ is the chamber volume, $F$ is the flow rate of air through 161 the chamber, $\mathrm{t}$ is the time step, and $\mathrm{E}$ is the emission rate, which is solved by the equation using least162 square fitting to the measured data. The shoot emissions were corrected for leaf dry mass of measured 163 shoot and stem emissions for covered bark area at the end of growing season.

164 Some of the sample air was also directed to the infrared light absorption analysers (URAS 4, Hartmann \& 165 Braun, Frankfurt am Main, Germany), which determined the water vapour and $\mathrm{CO}_{2}$ concentrations in the 166 sample air. In addition, both the ambient temperature near the tree canopies and the internal 167 temperature of the chambers, along with the relative humidity were monitored continuously. Stomatal 168 conductance $(\mathrm{G})$ was calculated as the division between measured transpiration (ET) and vapour pressure 169 deficit (VPD).

170 We omitted any data taken when the relative humidity $(\mathrm{RH})$ of the chamber was over $70 \%$ prior to data 171 analysis. High humidity in chamber causes condensation of water and its absorption on water-soluble 172 compounds, making the flux data unreliable.

173 We examined the effects of chamber temperature, ambient temperature, transpiration and stomatal 174 conductance on shoot emissions of methanol, acetone and acetaldehyde by regression analysis for both 
175 the entire growing season and monthly periods. The effect of temperature was calculated as described by 176 Guenther et al., (1995) (Eqn 2).

$$
E_{T}=E_{S} * \exp ^{\left[\beta\left(T-T_{S}\right)\right]}
$$

$\mathrm{K}, \mathrm{T}$ is the temperature inside chamber (in $\mathrm{K}$ ) and $\mathrm{T}_{\mathrm{S}}$ is a reference temperature (303 K). $\beta$ is an empirical parameter for the temperature sensitivity. We optimised $\beta$ for each study period and compound for the best fit of temperature model. The effect of transpiration on emissions was best explained by a linear regression, whereas the effect of stomatal conductance was best explained by an exponential function.

185 We first tested the goodness of each independent variable ( $T$, ET and G) for explaining the emissions 186 separately (Table 1, functions 1-3). Secondly, we tested the combinations of temperature and 187 transpiration ( $T+E T)$, and temperature and stomatal conductance $(T+G)$ (Table 1, functions $4-5)$. In the 188 models (Table 1), $a$ is an intercept and $b$ - $d$ are coefficients that were set freely to obtain the best fit for 189 the models. The regression models explaining the OVOC emissions were evaluated based on their coefficient of determination (R2). We also analysed the effects of temperature and transpiration on stem emissions by testing the regressions at different time lags, and studied the similarity between the emission

192 dynamics (shoot and stem) of the three compounds by Pearson's correlation. These analyses were made 193 in Matlab (version R2017a, The MathWorks, Inc.).

\section{TABLE 1}

195 We used structural equation modelling (SEM) using the $R$ lavaan package ( $R$ version 3.3.1, and the $R$ 196 Foundation for Statistical Computing) (Rosseel, 2012) to analyse further the interrelations between 
temperature, transpiration and stomatal conductance in explaining the emissions of OVOCs. The SEM model is used for normal distribution and linear relations, thus we normalised the transpiration data and emission data of all compounds by using the square roots of their values. Temperature and stomatal conductance data did not need transformations as they were normally distributed. We built two models,

201 the first one following the suggestion by Niinemets et al., (2003) whereby temperature and stomatal 202 conductance explain the emissions of water-soluble OVOCs. In the second model we included the effect

203 of transpiration that describes transport in xylem sap. The goodness of fit of the two SEM models were 204 evaluated by the R2 for emissions, and the comparative fit index (CFI) and the Tucker-Lewis index (TLI) 205 needed to be close to 1. The interrelation between the variables in the SEM models and their importance 206 in the models were evaluated by their estimated standardized parameter values in each regression and $p$ 207 values attributed to the parameter values. P-values below 0.05 were regarded as statistically significant.

208 We picked data sets from periods that had sufficient numbers of data points to represent diurnal or seasonal dynamics, and that covered the different measurement years to illustrate the dynamics of OVOC emissions from shoots and stems (March-October 2013), emission correlations to temperature,

211 transpiration and stomatal conductance (May-August 2010), the regression model fits $\left(9^{\text {th }}-12^{\text {th }}\right.$ of June 212 and $16^{\text {th }}-19^{\text {th }}$ of August 2015.), and SEM model functioning (May-September 2014).

\section{Results}

214 Shoot emissions of methanol, acetone and acetaldehyde had both clear seasonal and diurnal patterns that 215 were similar throughout all the five studied growing seasons. For example, the seasonal pattern was clearly 216 manifested in 2013. The start of growing seasons in early May drastically increased the shoot emissions of 217 methanol, acetaldehyde and acetone (Fig. 2, a, c, and e). The emissions further increased through June 218 and then started to decrease in mid-July. Emissions steadily decreased starting from the later part of 219 August, although a few peaks were still observed. The shoot emission dynamics of the three compounds 
were very similar to each other throughout the five growing seasons and the acetone and acetaldehyde

221 emissions correlated very closely, although the acetone emissions were larger (Fig. 2, a, c, and e, Table 2).

222 The shoot emissions during the growing season were highest in the daytime, at night the emissions were

223 low but usually still positive (Fig. 2, a, c, and e inserts). We observed shoot uptake only occasionally in early

224 May and in late August (Fig. 2, a, c and e). We did not detect clear morning bursts of any of the three

225 compounds.

TABLE 2

Stem emissions of methanol, acetone and acetaldehyde at 12 metres also had a clear seasonal and some diurnal variation during the growing season 2013 (Fig. 2, b, d, f). Emissions started to increase in mid-May. Acetaldehyde emissions peaked at the end of June and methanol emissions peaked in early July. The emissions of all the compounds increased slightly again at the end of July before decreasing towards the autumn. The stem emissions of the three compounds were not as similar as was the case for the shoot emissions (Table 2). From mid-May to August, emissions were usually highest in day-time and lowest at night, depending on the compound (Fig. 2, b, d, f and inserts). In April 2013, we found that stem emissions

234 of all three compounds increased with increasing stem height, the biggest difference being between 12 and 16.5 metres (Fig. 3). The baseline stem emissions of acetone and acetaldehyde were nevertheless quite small at that time, and we observed clear diurnal patterns only at 16.5 metres. The methanol emissions were larger and had clear diurnal pattern at all heights.

Temperature and transpiration rate best explained the shoot emissions of methanol, acetone and acetaldehyde during all the studied periods (Tables 3-5). The effect of temperature was exponential, and on average, explained $70 \%$ of methanol, $51 \%$ of acetaldehyde and $62 \%$ of the acetone emission variation

(Fig. 4, Tables 3-5, model T). Transpiration had a linear effect on the emissions, and on average, explained 
243 ET). The effect of stomatal conductance on the mean emissions of the OVOCs was also exponential but

244 smaller: stomatal conductance, on average, explained only $10 \%$ of methanol and $16 \%$ of acetaldehyde and

245 acetone emission variation (Fig. 4, Tables 3-5, model G). These effects were well presented, for example,

246 in 2010 (Fig. 4). In addition, the emissions seemed to be regulated by stomatal conductance only when

247 stomatal conductance decreased to $0.25 \mathrm{dm}^{3} \mathrm{~s}^{-1} \mathrm{~m}^{-2}$ or below, at nigh time (Fig. 4, grey line). At higher

248 conductance, the emissions were determined either by temperature or transpiration rate. During the

249 exemplar growing season of 2010 , we observed slight shifts in the temperature, transpiration and stomatal

250 relations of methanol, acetone and acetaldehyde emissions (Fig. 4, Tables 3-5). In May and June, the

251 temperature sensitivities of especially acetaldehyde and acetone emissions were higher than later in the

252 summer. The sensitivity of methanol emissions to transpiration rate also increased in May and June. In

253 addition, stomatal conductance seemed to affect all the compounds more in July and August than in early

254 summer.

255 Of the all regression models (Table 1), the model that combined temperature and transpiration (model

256 T+ET) best explained the emissions of all three compounds (Tables 3-5) and produced smallest root mean

257 square error (Supporting information Tables S1-S3). For acetone and acetaldehyde emissions, model T+ET

258 was usually considerably better than model T+G, but close to model ET (Tables 4-5, Supporting information

259 Fig. S1). In contrast, for methanol, the differences between model $T$, model $T+E T$ and model $T+G$ were

260 small in most periods (Table 3, Supporting information Fig. S1). The error degrees of freedom of all the

261 models ranged from 278 to 2310 depending on the period analysed (Supporting information Table S4).

262 TABLES 3-5

263 Temperature and transpiration affected the stem emission less than they affected shoot emissions, and

264 with certain time lags. The temperature explained $33 \%$ of variation in methanol emissions without a time

265 lag and 32\% of variation in acetaldehyde emissions at a time lag of approximately 3 hours (data not shown). 
Acetone emissions did not correlate with temperature. Transpiration explained only $16 \%$ of variation in methanol emissions at a time lag of approximately 5 hours and $11 \%$ of variation in acetone emissions at a time lag of approximately 8 hours (data not shown). Acetaldehyde emissions did not correlate with transpiration. The correlation of methanol emissions with temperature was slightly stronger in the lower stem (0.70 at 7 metres) than in the upper stem (0.59 at 12 metres and 0.62 at 16.5 metres) in April 2013.

271 In addition to the regression models, we used structural equation modelling (SEM) to examine the effects

272 and interrelations of transpiration, temperature and stomatal conductance in explaining OVOC emissions.

273 The temperature and stomatal conductance were used in the first SEM to explain emissions (Fig. 5, a-c).

274 These models show a major impact of temperature, and a minor impact of stomatal conductance on the

275 emissions of methanol, acetaldehyde and acetone. Transpiration, affected by temperature and stomatal

276 conductance, was added to the second SEM models (Fig. 5, d-f). Adding transpiration revealed that a

277 proportion of temperature's effect on emissions was mediated through transpiration, especially for

278 acetaldehyde and acetone emissions. Moreover, transpiration almost completely covered the effect of 279 stomatal conductance so that the direct effect of stomatal conductance even became negative (Fig. 5, d, 280 e and f).

283 We found that during the growing seasons, the diurnal patterns of methanol, acetone and acetaldehyde 284 emissions from shoots closely followed the dynamics of transpiration and temperature. Similar shoot 285 emission patterns in field conditions have been reported for methanol by Folkers et al., (2008) (Quercus 286 robur), and for acetone and acetaldehyde by Cojocariu et al., (2004) and Grabmer et al., (2006) in Picea 287 abies. Stem emissions from the top part of the stem (at 12 metres) also followed a temperature related 288 diurnal pattern, but less clearly. 
289 We did not observe clear morning bursts of any of the compounds from Scots pine shoots, or from 290 shoots of deciduous species (Populus tremuloides and Betula pendula) measured at the same site (data 291 not shown). Harley et al., (2007) also reported unnoticeable or small bursts form Pinus taeda and Pinus

292 sabiniana. The lack of morning bursts contrasts with results reported by Mac Donald et al., (1993)

293 (Populus tremuloides), Harley et al., (2007), (Populus deltoides, Sorghum bicolor, Magnifera indica) and

294 Folkers et al., (2008) (Quercus robur, Fagus sylvatica, Betula pendula) in laboratory setting and Saunier et 295 al., (2017) (Quercus pubescens) in field conditions in Southern France, and questions the role of stomatal 296 conductance in regulating emissions in boreal forest. In the moist boreal conditions, the stomata can

297 remain partly open even at night. Thus, there are positive night-time emissions and compounds do not 298 accumulate inside leaves, or any accumulation is released gradually together with the slow increase of 299 irradiation in the morning.

301 An exponential temperature dependence is common for VOC emissions, and has been reported for 302 methanol (Hayward et al., 2004; Filella et al., 2007; Harley et al., 2007; Folkers et al., 2008; Saunier et al., 303 2017), acetone (Cojocariu et al., 2004; Filella et al., 2007; Saunier et al., 2017) and acetaldehyde (Hayward 304 et al., 2004; Filella et al., 2007; Saunier et al., 2017). OVOC emissions have also been linked to 305 photosynthetically active radiation (PAR) (Grabmer et al., 2006; Saunier et al., 2017). However, Oikawa et 306 al., (2011) and Folkers et al., (2008) reported that over short timescales methanol emissions are not 307 induced by light per se, but the light effect on emissions is indirect. We observed a linear association 308 between PAR and especially acetaldehyde emissions, but its effect was smaller than that of transpiration, 309 so it was not analysed further. We found only weak connections between stomatal conductance and 310 emissions of methanol, acetone and acetaldehyde, contrary to the results reported earlier (Kreuzwieser 311 et al., 2000; Filella et al., 2007, 2009; Harley et al., 2007), but instead a clear linear effect of transpiration, 312 as reported by Harley et al., (2007), Folkers et al., (2008) and Filella et al., (2007) for methanol, Cojocariu 
313 et al., (2004) for acetone and Kreuzwieser et al., (2001), Cojocariu et al., (2004) and Filella et al., (2007) for

314 acetaldehyde.

315 In effect, in combination with temperature, transpiration seemed to directly regulate the shoot emissions

316 of methanol, and especially acetaldehyde and acetone. This was apparent in the regression models where

317 transpiration was the best parameter to explain the acetone and acetaldehyde emissions, and enhanced

318 the emissions model based on temperature also for methanol. The SEM model further confirmed the role

319 of transpiration: of the three tested variables: temperature, transpiration and stomatal conductance,

320 transpiration had the largest effect on the emissions of acetone and acetaldehyde and, slightly after

321 temperature, the second largest effect on the emissions of methanol. However, although temperature has

322 an important direct effect on emissions by regulating tree metabolic rates, as well as the diffusion rates

323 and vapour pressures of the compounds, we observed that a large part of its effect was mediated through

324 transpiration. In addition, stomatal conductance affected emissions only by regulating transpiration.

325 The strong effect of transpiration on the emissions of methanol, acetone and acetaldehyde clearly

326 indicates that these compounds or their precursors can be transported from their sources in the roots and

327 stem to the leaves in the xylem sap. We also observed a small positive effect of transpiration on the stem

328 emissions of methanol and acetone, although temperature explained the emissions usually better. The

329 lags in both temperature and transpiration effects were due to the diffusion resistance though the wood

330 and bark. The transpiration effect corresponded with what has been observed for $\mathrm{CO}_{2}$ emissions in the

331 topmost part of the stem of the same trees (Hölttä \& Kolari, 2009) and it implies that increasing

332 transpiration increases the transport of water soluble compounds to that area and subsequently their

333 emissions. The transport hypothesis also fits well with the observed stem emission patterns: emissions

334 increased towards the stem top. 
335 The different production locations of methanol, acetaldehyde and acetone define their diffusion 336 resistances and probably create the small differences we observed in their emission dynamics from shoots 337 and stem. Methanol that is produced close to surface in growing tissue (Galbally \& Kristine, 2002; Hüve et 338 al., 2007) has a short diffusion pathway and is thus less prone to partition to xylem water. Therefore, its 339 shoot emissions are less affected by transpiration despite its high water-solubility. This is somewhat in 340 accordance with Folkers et al., (2008), who suggested that transport in transpiration water is probably not 341 the main factor in regulating methanol emissions. Acetaldehyde's precursor ethanol originates mainly 342 from anaerobic conditions (Kreuzwieser et al., 1999, 2000); thus, its diffusion pathway is longer, and it is 343 more likely to partition into water phase. Consequently, its shoot emissions are dependent on 344 transpiration, which has been detected before (Kreuzvieser et al., 2000, 2001). The production of 345 methanol near stem surface also explains its large emissions form all stem heights compared to acetone 346 and acetaldehyde, although the shoot emissions of methanol and acetaldehyde are on the same scale, 347 acetone emissions being largest.

348 The most important limitations in this study arise from using the dynamic chamber and the PTR-MS 349 measurement modalities that contains a possible underestimation of $5-30 \%$ for the fluxes (Kolari et al., 350 2012). However, the effect of these uncertainties diminishes due to the quantity of data over the five 351 growing seasons studied. Based on long-term field measurements, we conclude that along with 352 temperature, transpiration directly regulates the shoot emissions of the water-soluble compounds 353 methanol, acetaldehyde and acetone. Stomatal conductance under field conditions only has an indirect 354 effect through the regulation of transpiration especially during night time. The important role of 355 transpiration on the OVOC shoot emissions implies that a proportion of them originate from roots and 356 stem and are transported to the leaves in the xylem sap. The effect of transport on shoot scale emissions 357 and stem emissions depends on the production locations and water solubility of the compounds. More 358 specialized field and laboratory experiments should be performed to understand the process of transport 
359 of water soluble compounds in detail, and to quantify the proportions of the transported compounds from

360 the total shoot emissions.

361 Acknowledgements:

362 This research was funded by The Academy of Finland Center of Excellence programme (grant no.307331)

363 and the University of Helsinki Research Foundation. We wish to thank Juho Aalto for his work with the

364 long-term shoot flux measurements at the SMEAR II station, Anni Vanhatalo for her work with the stem

365 flux measurements, and the whole SMEAR II technical staff for their assistance and maintenance of all

366 the long-term measurements at the station. The authors have no conflicts of interest to declare. 


\section{References}

377 Aalto J., Kolari P., Hari P., Kerminen V.-P., Schiestl-Aalto P., Aaltonen H., ..., Bäck J. (2014) New foliage

378 growth is a significant, unaccounted source for volatiles in boreal evergreen forests. Biogeosciences 11, $379 \quad 1331-1344$.

380 Bloemen J., Mcguire M.A., Aubrey D.P., Teskey R.O. \& Steppe K. (2013) Transport of root-respired CO2

381 via the transpiration stream affects aboveground carbon assimilation and $\mathrm{CO} 2$ efflux in trees. New

382 Phytologist 197, 555-565.

383 Boysen-Jensen, P. (1933) Respiration I stamme og grene af traer. Sven Skogsvards Tidskr 31, 239-241.

384 Bowman W.P., Barbour M.M., Turnbull M.H., Tissue D.T., Whitehead D. \& Griffin K.L. (2005) Sap flow

385 rates and sapwood density are critical factors in within- and between-tree variation in $\mathrm{CO} 2$ efflux from

386 stems of mature dacrydium cupressinum trees. New Phytologist 167, 815-828.

387 Cojocariu C., Kreuzwieser J. \& Rennenberg H. (2004) Correlation of short-chained carbonyls emitted from 388 picea abies with physiological and environmental parameters. New Phytologist 162, 717-727.

389 Copolovici L. \& Niinemets Ü. (2010) Flooding induced emissions of volatile signalling compounds in three 390 tree species with differing waterlogging tolerance. Plant, Cell and Environment 33, 1582-1594.

391 Fall R. (2003) Abundant oxygenates in the atmosphere: A biochemical perspective. Chemical Reviews $392103,4941-4951$.

393 Fall R. \& Benson A.A. (1996) Leaf methanol - the simplest natural product from plants. Trends in Plant 394 Science 1, 296-301. 
395 Filella I., Peñuelas J. \& Seco R. (2009) Short-chained oxygenated VOC emissions in pinus halepensis in 396 response to changes in water availability. Acta Physiologiae Plantarum 31, 311-318.

397 Filella I., Wilkinson M.J., Llusià J., Hewitt C.N. \& Peñuelas J. (2007) Volatile organic compounds emissions 398 in norway spruce (picea abies) in response to temperature changes. Physiologia Plantarum 130, 58-66.

399 Folkers A., Hüve K., Ammann C., Dindorf T., Kesselmeier J., Kleist E.,..., Wildt J. (2008) Methanol 400 emissions from deciduous tree species: Dependence on temperature and light intensity. Plant Biology $401 \quad 10,65-75$.

402 Galbally I.E. \& Kirstine W. (2002) The production of methanol by flowering plants and the global cycle of 403 methanol. Journal of Atmospheric Chemistry 43, 195-229.

404 Gansert D. \& Burgdorf M. (2005) Effects of xylem sap flow on carbon dioxide efflux from stems of birch 405 (Betula pendula roth). Flora: Morphology, Distribution, Functional Ecology of Plants 200, 444-455.

406 Grabmer W., Kreuzwieser J., Wisthaler A., Cojocariu C., Graus M., Rennenberg H., ..., Hansel A. (2006)

407 VOC emissions from norway spruce (Picea abies L. [karst]) twigs in the field-results of a dynamic 408 enclosure study. Atmospheric Environment 40, 128-137.

409 Guenther A. (1995) A global model of natural volatile organic compound emissions. Journal of $410 \quad$ Geophysical Research 100, 8873-8892.

411 Guenther A.B., Zimmerman P.R., Harley P.C., Monson R.K. \& Fall R. (1993) Isoprene and monoterpene 412 emission rate variability: Model evaluations and sensitivity analyses. Journal of Geophysical Research 98, $413 \quad 12,609-12,617$. 
414 Hari P., Keronen P., Bäck J., Altimir N., Linkosalo T., Pohja T., Kulmala M. \& Vesala T. (1999) An

415 improvement of the method for calibrating measurements of photosynthetic CO2 flux. Plant, Cell \& 416 Environment 22, 1297-1301.

417 Hari P., Nikinmaa E., Pohja T., Siivola E., Bäck J., Vesala T. \& Kulmala M. (2013) Station for measuring 418 ecosystem-atmosphere relations: SMEAR. In Station for measuring ecosystem-atmosphere relations: 419 SMEAR. pp. 471-487.

420 Harley P., Greenberg J., Niinemets Ü \& Guenther A. (2007) Environmental controls over methanol 421 emission from leaves. Biogeosciences 4, 1083-1099.

422 Hayward S., Tani A., Owen S.M. \& Hewitt C.N. (2004) Online analysis of volatile organic compound 423 emissions from sitka spruce (picea sitchensis). Tree Physiology 24, 721-728.

424 Hölttä T. \& Kolari P. (2009) Interpretation of stem CO2 efflux measurements. Tree Physiology 29, 14474251456.

426 Hüve K., Christ M.M., Kleist E., Uerlings R., Niinemets Ü, Walter A. \& Wildt J. (2007) Simultaneous growth 427 and emission measurements demonstrate an interactive control of methanol release by leaf expansion 428 and stomata. Journal of Experimental Botany 58, 1783-1793.

429 Ilvesniemi H., Pumpanen J., Duursma R., Hari P., Keronen P., Kolari P. ,..., Vesala T. (2010) Water balance 430 of a boreal scots pine forest. Boreal Environment Research 15, 375-396.

431 Jardine K., Harley P., Karl T., Guenther A., Lerdau M. \& Mak J.E. (2008) Plant physiological and 432 environmental controls over the exchange of acetaldehyde between forest canopies and the 433 atmosphere. Biogeosciences 5, 1559-1572. 
434 Karl T., Curtis A.J., Rosenstiel T.N., Monson R.K. \& Fall R. (2002) Transient releases of acetaldehyde from 435 tree leaves-products of a pyruvate overflow mechanism? Plant, Cell and Environment 25, 1121-1131.

436 Kolari P., Bäck J., Taipale R., Ruuskanen T.M., Kajos M.K., Rinne J., Kulmala M. \& Hari P. (2012) Evaluation 437 of accuracy in measurements of VOC emissions with dynamic chamber system. Atmospheric Environment $438 \quad 62,344-351$.

439 Kreuzwieser J., Harren F.J.M., Laarhoven L.J.J., Boamfa I., Lintel-Hekkert S.T., Scheerer U., Hüglin C. \& 440 Rennenberg H. (2001) Acetaldehyde emission by the leaves of trees - correlation with physiological and 441 environmental parameters. Physiologia Plantarum 113, 41-49.

442 Kreuzwieser J., Kühnemann F., Martis A., Rennenberg H. \& Urban W. (2000) Diurnal pattern of 443 acetaldehyde emission by flooded poplar trees. Physiologia Plantarum 108, 79-86.

444 Kreuzwieser J., Scheerer U. \& Rennenberg H. (1999) Metabolic origin of acetaldehyde emitted by poplar 445 (Populus tremuls x P. alba) trees. Journal of Experimental Botany 335, 757-765.

446 Loreto F., Barta C., Brilli F. \& Nogues I. (2006) On the induction of volatile organic compound emissions 447 by plants as consequence of wounding or fluctuations of light and temperature. Plant, Cell and 448 Environment 29, 1820-1828.

449 MacDonald R.C. \& Fall R. (1993) Detection of substantial emissions of methanol from plants to the 450 atmosphere. Atmospheric Environment Part A, General Topics 27, 1709-1713.

451 MacDonald R.C. \& Kimmerer T.W. (1991) Ethanol in the stems of trees. Physiologia plantarum 82, 582452588. 
453 McGuire M.A., Cerasoli S. \& Teskey R.O. (2007) CO2 fluxes and respiration of branch segments of

454 sycamore (platanus occidentalis L.) examined at different sap velocities, branch diameters, and

455 temperatures. Journal of Experimental Botany 58, 2159-2168.

456 McGuire M.A. \& Teskey R.O. (2004) Estimating stem respiration in trees by a mass balance approach that

457 accounts for internal and external fluxes of CO2. Tree Physiology 24, 571-578.

458 Nemecek-Marshall M., MacDonald R.C., Franzen J.J., Wojciechowski C.L. \& Fall R. (1995) Methanol

459 emission from leaves. enzymatic detection of gas-phase methanol and relation of methanol fluxes to

460 stomatal conductance and leaf development. Plant Physiology 108, 1359-1368.

461 Niinemets Ü, Loreto F. \& Reichstein M. (2004) Physiological and physicochemical controls on foliar

462 volatile organic compound emissions. Trends in Plant Science 9, 180-186.

463 Niinemets Ü \& Reichstein M. (2003) Controls on the emission of plant volatiles through stomata:

464 Differential sensitivity of emission rates to stomatal closure explained. Journal of Geophysical Research $465108, \mathrm{ACH} 2-1 \mathrm{ACH} 2-17$.

466 Oikawa P.Y., Li L., Timko M.P., Mak J.E. \& Lerdau M.T. (2011) Short term changes in methanol emission

467 and pectin methylesterase activity are not directly affected by light in lycopersicon esculentum.

468 Biogeosciences 8, 1023-1030.

469 Peñuelas J., Filella I., Stefanescu C. \& Llusià J. (2005) Caterpillars of euphydryas aurinia (lepidoptera:

470 Nymphalidae) feeding on succisa pratensis leaves induce large foliar emissions of methanol. New

471 Phytologist 167, 851-857.

472 Rosseel, Y. (2012). lavaan: An R Package for Structural Equation Modeling. Journal of Statistical Software $47348,1-36$. 
474 Saunier A., Ormenõ E., Boissard C., Wortham H., Temime-Roussel B., Lecareux C., Armengaud A. \&

475 Fernandez C. (2017) Effect of mid-term drought on quercus pubescens BVOCs' emission seasonality and 476 their dependency on light and/or temperature. Atmospheric Chemistry and Physics 17, 7555-7566.

477 Seco R., Peñuelas J. \& Filella I. (2007) Short-chain oxygenated VOCs: Emission and uptake by plants and

478 atmospheric sources, sinks, and concentrations. Atmospheric Environment 41, 2477-2499.

479 Simpson D., Guenther A., Hewitt C.N. \& Steinbrecher R. (1995) Biogenic emissions in Europe: estimates 480 and uncertainties. Journal of Geophysical Research 100, 22,875-22,890.

481 Vanhatalo A., Chan T., Aalto J., Korhonen J.F., Kolari P., Hölttä T., Nikinmaa E. \& Bäck J. (2015) Tree water 482 relations can trigger monoterpene emissions from scots pine stems during spring recovery.

483 Biogeosciences 12, 5353-5363.

484 Warneke C., Karl T., Judmaier H., Hansel A., Jordan A., Lindinger W. \& Crutzen P.J. (1999) Acetone, 485 methanol, and other partially oxidized volatile organic emissions from dead plant matter by abiological 486 processes: Significance for atmospheric $\mathrm{HO}(\mathrm{X})$ chemistry. Global Biogeochemical Cycles 13, 9-17. 
Table 1: Functions used in regression models to explain emissions ( $E$ ) of methanol, acetone and acetaldehyde from Scots pine shoots by temperature, transpiration and stomatal conductance at the SMEAR II station in Hyytiälä, Southern Finland. $E_{\text {model }}=$ estimated emissions, T=temperature,

504 ET=evapotranspiration, $\mathrm{G}=$ stomatal conductance, $a=$ changing empirical intercept, optimized for the best 505 fit in each model, $b-d=$ changing empirical coefficients, optimized for the best fit in each model, $506 \beta=$ =mpirical coefficient for temperature sensitivity, optimized for best fit in model T (1))

$1 \quad E_{\operatorname{model} T}=a+b * \exp ^{[\beta(T-303)]}$

$2 \quad E_{\text {model ET }}=a+b * E T$

$3 E_{\text {model } G}=a+b * \exp ^{[c * G]}$

$4 \quad E_{\text {model } T+E T}=a+b * \exp ^{[\beta(T-303)]}+c * E$ 
520

521

522

523

524

525

526

527 Table 2. Pearson's correlation coefficients ( $r$ ) between Scots pine shoot emissions of acetaldehyde,

528 methanol and acetone during the years 2010-2011 and 2013-2015, and stem emissions in 2013, at the

529 SMEAR II station, in Hyytiälä, Southern Finland. All correlations in the table are significant $(p<0.05)$.

\begin{tabular}{l|lll} 
Year & $\begin{array}{l}\text { Acetaldehyde- } \\
\text { Methanol }\end{array}$ & $\begin{array}{l}\text { Acetaldehyde- } \\
\text { Acetone }\end{array}$ & $\begin{array}{l}\text { Acetone- } \\
\text { Methanol }\end{array}$ \\
\hline 2010 & 0.89 & 0.95 & 0.94 \\
2011 & 0.88 & 0.94 & 0.82 \\
2013 & 0.94 & 0.97 & 0.95 \\
2014 & 0.62 & 0.62 & 0.86 \\
2015 & 0.87 & 0.93 & 0.9 \\
2013 (stem) & 0.50 & 0.53 & 0.53
\end{tabular}

530

531

532

533 
536 Table 3. The coefficients of determination (R2) of regression models that explain methanol shoot 537 emissions from Scots pine with temperature $(\mathrm{T})$, transpiration (ET) and stomatal conductance (G) and 538 combinations ( $T+E T$ and $T+G)$ over five growing seasons at the SMEAR II station in Hyytiälä, Southern 539 Finland. The beta value for the temperature functions is shown in parenthesis after the temperature 540 model's coefficient. The R2 of model with the best fit is indicated in bold. The model functions are 541 presented in Table 1.

\begin{tabular}{r|llccc} 
Year & Model T & Model ET & Model G & $\begin{array}{l}\text { Model } \\
\text { T+ET }\end{array}$ & $\begin{array}{l}\text { Model } \\
\text { T+G }\end{array}$ \\
\hline 2010 & & & & & 0.87 \\
May & $0.82(0.06)$ & 0.63 & 0.00 & $\mathbf{0 . 8 7}$ & 0.85 \\
June & $0.76(0.07)$ & 0.68 & 0.05 & $\mathbf{0 . 9 3}$ & 0.91 \\
July & $0.88(0.05)$ & 0.66 & 0.05 & $\mathbf{0 . 9 1}$ & 0.90 \\
August & $0.64(0.02)$ & 0.73 & 0.10 & $\mathbf{0 . 8 3}$ & 0.72 \\
2011 & $0.39(0.00)$ & 0.55 & 0.26 & $\mathbf{0 . 5 6}$ & 0.54 \\
2013 & $0.68(0.09)$ & 0.59 & 0.16 & $\mathbf{0 . 7 6}$ & 0.72 \\
2014 & $0.84(0.12)$ & 0.60 & 0.02 & $\mathbf{0 . 8 8}$ & 0.86 \\
2015 & $\mathbf{0 . 7 8 ( 0 . 1 2 )}$ & 0.56 & 0.05 & $\mathbf{0 . 7 8}$ & 0.76
\end{tabular}


553 Table 4. The coefficients of determination (R2) of regression models that explain acetaldehyde shoot 554 emissions from Scots pine with temperature (T), transpiration (ET) and stomatal conductance (G) and 555 combinations ( $T+E T$ and $T+G)$ over five growing seasons at the SMEAR II station in Hyytiälä, Southern 556 Finland. The beta value for the temperature functions is shown in parenthesis after the temperature 557 model's coefficient. The R2 of model with the best fit is indicated in bold. The model functions are 558 presented in Table 1.

\begin{tabular}{|c|c|c|c|c|c|}
\hline Year & Model T & Model ET & Model G & $\begin{array}{c}\text { Model } \\
\text { T+ET }\end{array}$ & $\begin{array}{c}\text { Model } \\
T+G\end{array}$ \\
\hline 2010 & $0.52(0.04)$ & 0.72 & 0.05 & 0.75 & 0.61 \\
\hline May & $0.74(0.10)$ & 0.68 & 0.02 & 0.82 & 0.77 \\
\hline June & $0.49(0.02)$ & 0.58 & 0.03 & 0.68 & 0.58 \\
\hline July & $0.56(0.05)$ & 0.82 & 0.19 & 0.83 & 0.71 \\
\hline August & $0.50(0.03)$ & 0.78 & 0.17 & 0.81 & 0.66 \\
\hline 2011 & $0.45(0.00)$ & 0.79 & 0.35 & 0.79 & 0.65 \\
\hline 2013 & $0.58(0.12)$ & 0.63 & 0.21 & 0.73 & 0.68 \\
\hline 2014 & $0.31(0.12)$ & 0.31 & 0.03 & 0.37 & 0.33 \\
\hline 2015 & $0.68(0.12)$ & 0.71 & 0.15 & 0.76 & 0.68 \\
\hline
\end{tabular}

559

560

561

562

563

564

565 
569 Table 5. The coefficients of determination (R2) of regression models that explain acetone shoot

570 emissions from Scots pine with temperature (T), transpiration (ET) and stomatal conductance (G) and

571 combinations $(T+E T$ and $T+G)$ over five growing seasons at the SMEAR II station in Hyytiälä, Southern

572 Finland. The beta value for the temperature functions is shown in parenthesis after the temperature

573 model's coefficient. The R2 of model with the best fit is indicated in bold. The model functions are

574 presented in Table 1.

\begin{tabular}{|c|c|c|c|c|c|}
\hline Year & Model T & Model ET & Model G & $\begin{array}{c}\text { Model } \\
\text { T+ET }\end{array}$ & $\begin{array}{c}\text { Model } \\
T+G\end{array}$ \\
\hline 2010 & $0.57(0.05)$ & 0.75 & 0.07 & 0.79 & 0.70 \\
\hline May & $0.78(0.08)$ & 0.77 & 0.00 & 0.89 & 0.86 \\
\hline June & $0.49(0.04)$ & 0.64 & 0.11 & 0.72 & 0.69 \\
\hline July & $0.69(0.04)$ & 0.8 & 0.16 & 0.86 & 0.80 \\
\hline August & $0.54(0.02)$ & 0.85 & 0.24 & 0.88 & 0.77 \\
\hline 2011 & $0.67(0.07)$ & 0.76 & 0.22 & 0.82 & 0.76 \\
\hline 2013 & $0.57(0.11)$ & 0.62 & 0.24 & 0.72 & 0.69 \\
\hline 2014 & $0.44(0.09)$ & 0.41 & 0.05 & 0.50 & 0.47 \\
\hline 2015 & $0.83(0.11)$ & 0.79 & 0.20 & 0.91 & 0.87 \\
\hline
\end{tabular}




\section{Transpiration directly regulates the emissions of water-soluble short-chained}

\section{OVOCS}

Authors: Rissanen, K., Hölttä, T \& Bäck, J.

\section{Figure legends}

Figure 1. Schematic figure on how water-soluble compounds: carbon dioxide, methanol, acetone or acetaldehyde can diffuse into the ambient air or be partitioned into the xylem sap after being synthesized. After its synthesis at a certain production location such as the cambium (a), heartwood (b) or roots(c), the compound can either 1) diffuse through wood and bark (B) into the ambient air or 2) dissolve into the xylem sap $(X)$ and be transported upwards in a transpiration stream. With the accumulation of water soluble compounds in the xylem sap, the compounds can also 3) escape the aqueous phase and diffuse through wood and bark into the ambient air. This pathway is more preferred in the upper parts of stems as the concentration in xylem water is higher and the bark is thinner. As the compounds reach the leaves, they can be either metabolized or diffuse out into the ambient air through the stomata (4).

Figure 2: Shoot (left, a, c, e) and stem (right, b, d ,f) emissions of methanol (top, a, b), acetaldehyde (middle, c, d) and acetone (bottom, e, f) from Scots pine at the SMEAR II station, in Hyytiälä, Southern Finland, in 2013. The smaller inset figures are examples of diurnal variations of emissions from $15^{\text {th }}-17^{\text {th }}$ July, 2013. DW $=$ leaf dry weight, $\mathrm{BA}=$ bark area

Figure 3. Stem emissions of methanol (a), acetaldehyde (b) and acetone (c) at 7 and 12 metres (left axis) and at 16.5 metres above the ground (right axis) of Scots pine and temperature (d, left axis) measured in three stem chambers, evapotranspiration ( $d$, right axes) measured from the shoot of the same tree. $B A=$ bark area, $L A=$ leaf area. At SMEAR II station in Hyytiälä, Southern Finland, April $2^{\text {ndt }}-4^{\text {th }}, 2013$ 
Figure 4: Temperature $(a, d, g)$, transpiration $(b, e, h)$ and stomatal conductance $(c, f, i)$ effects on Scots pine shoot emissions of methanol (a-c), acetaldehyde (d-f) and acetone (g-i) at SMEAR II station in Hyytiälä, Southern Finland, during May, June, July and August 2010. The vertical grey line in the right panel figures indicate the point, below which stomatal conductance regulates emissions. DW = leaf dry weight, LA = leaf area. $\mathrm{R} 2$ for these relations are presented in Tables 3-5.

Figure 5. Structural equation models (SEM) on the effects of temperature, stomatal conductance and transpiration on methanol $(a, d)$, on acetaldehyde $(b, e)$ and on acetone $(c, f)$ shoot emissions from Scots pine, at SMEAR II station in Hyytiälä, Southern Finland during the 2014 growing season. Upper parts (a-c): Only temperature and stomatal conductance affected emissions. Lower parts ( $d-f)$ : Transpiration was added to the path model. The arrow weights and parameters indicate the estimated standardized parameter values that are significant $(p<0.05)$ unless in brackets. Standard error of the parameter value in parentheses. (sqrt) under a variable name indicates that square root transformation was made to obtain normal distribution. $\mathrm{R} 2$ in the left bottom corner is the whole model coefficient for the OVOC emissions' determination, $\mathrm{df}$ for the degrees of freedom. 


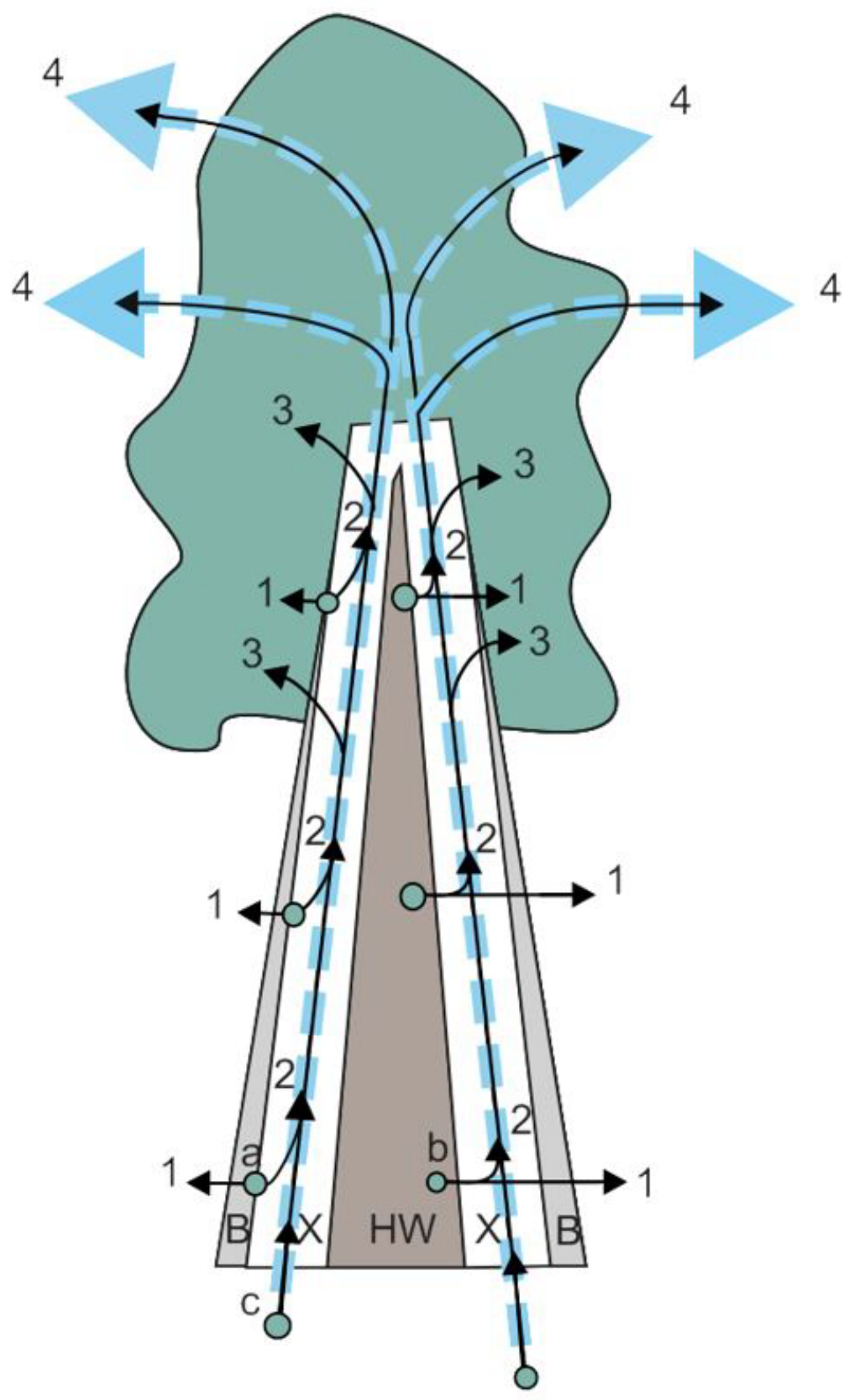

a: production in the cambium

b: production in the heartwood

c: production in the roots

HW: heart wood

$\mathrm{X}$ : xylem, xylem sap

B: bark

1: diffusion from the production

2: partitioning into the xylem sap

3: diffusion from the xylem sap

4: emissions through leaf stomata

Fig. 1 
Methanol
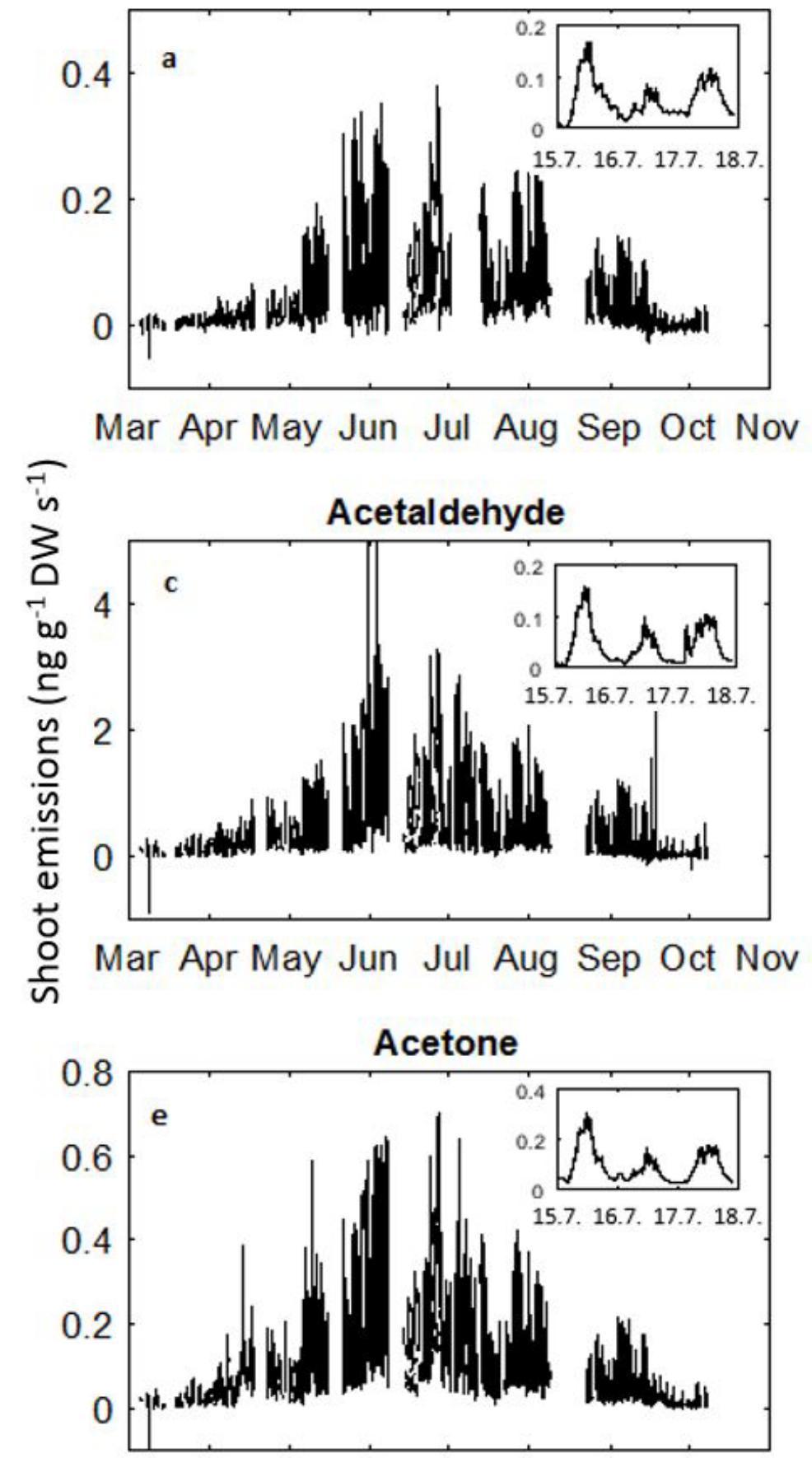

Mar Apr May Jun Jul Aug Sep Oct Nov

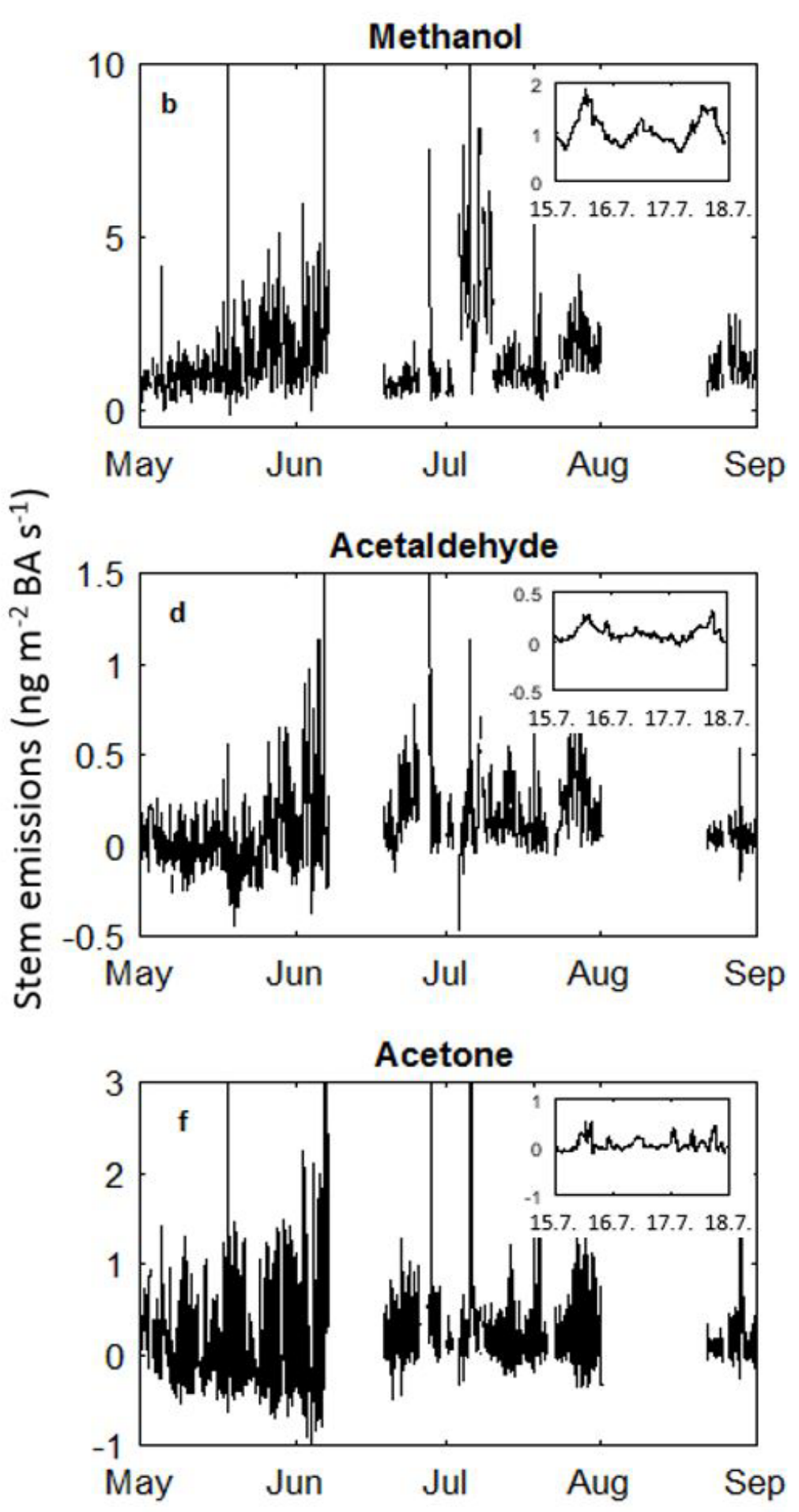

Fig. 2 


\begin{tabular}{|l|llll|}
\hline$\cdot$ May $\cdot$ June $\cdot$ July & August \\
\hline
\end{tabular}
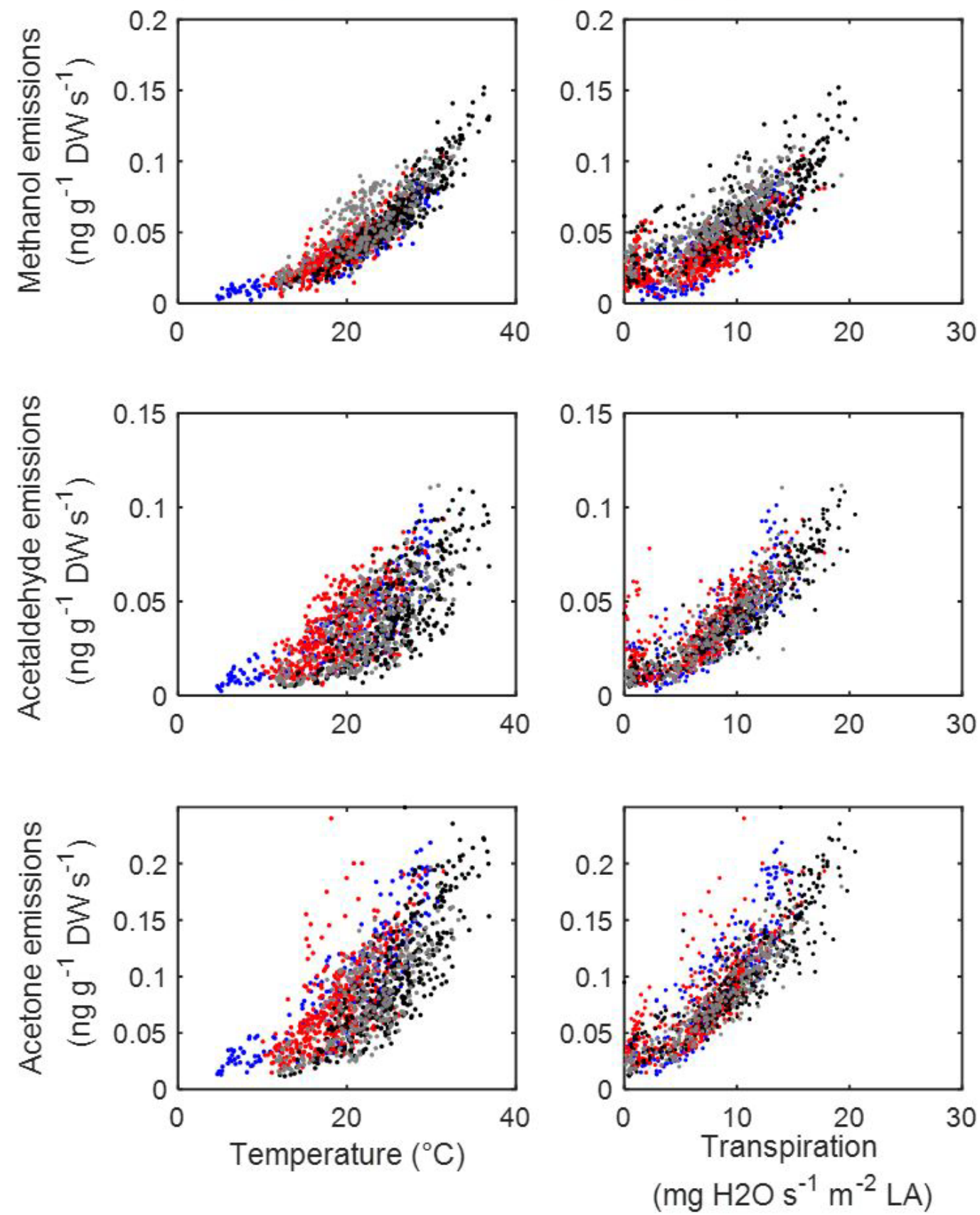

Fig. 4
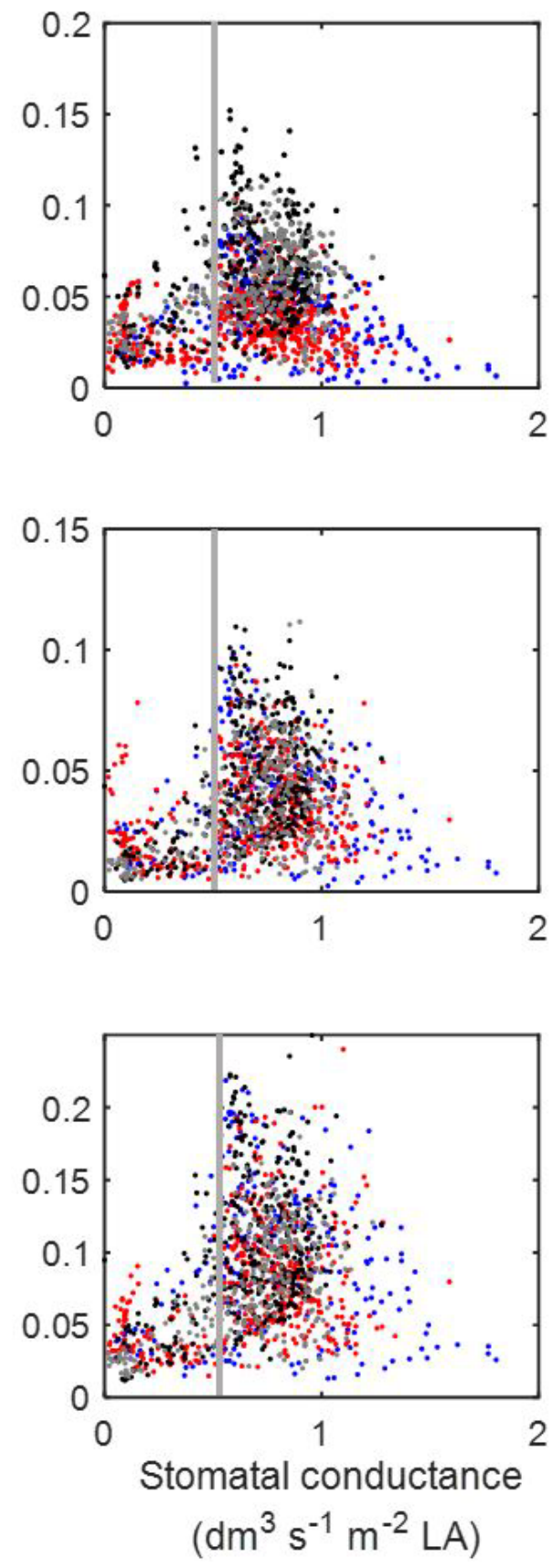

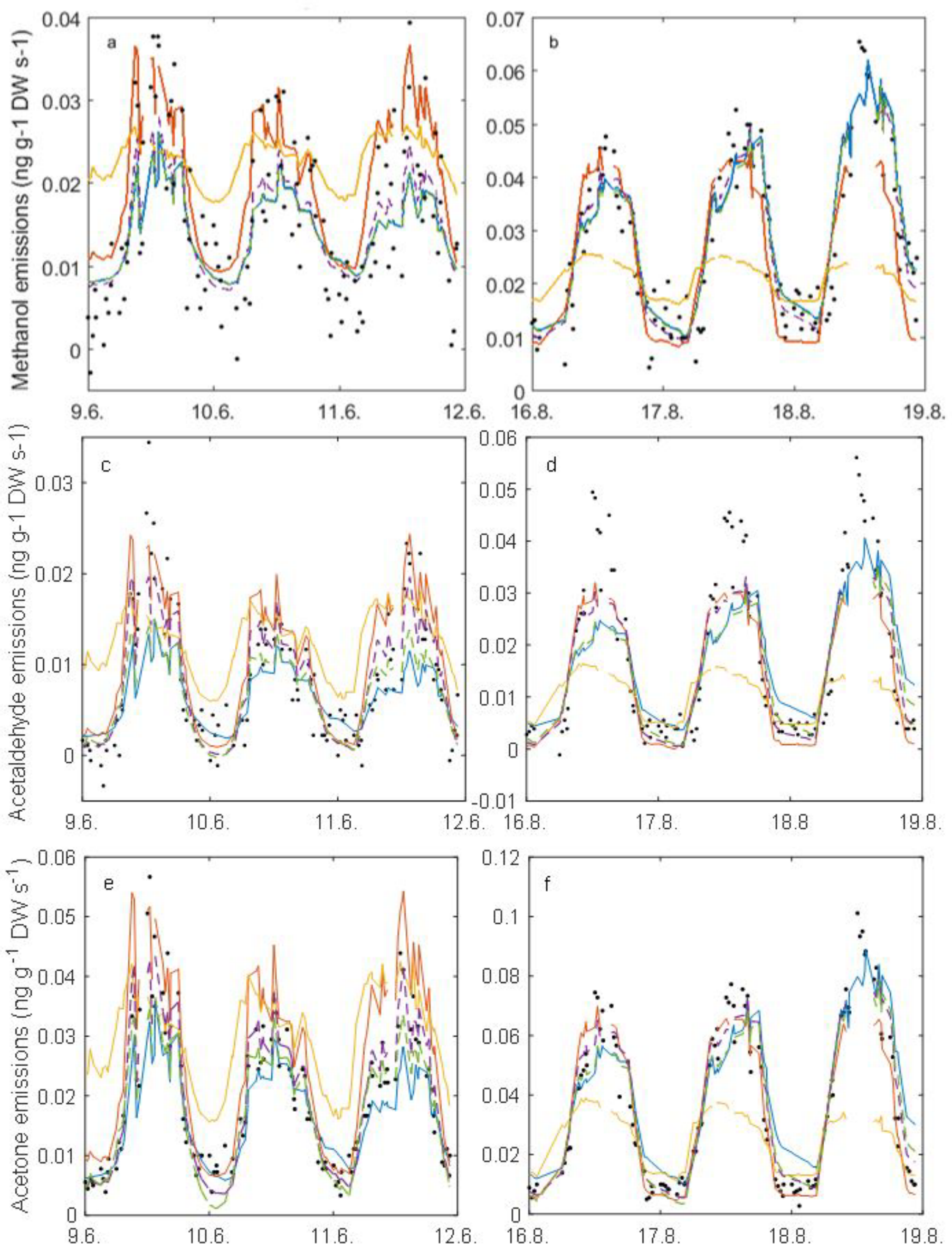

- measured —estimate $T$ - estimate ET - estimate $G$ - - -estimate $T+E T$ - - - estimate $T+G$

Fig. 5 


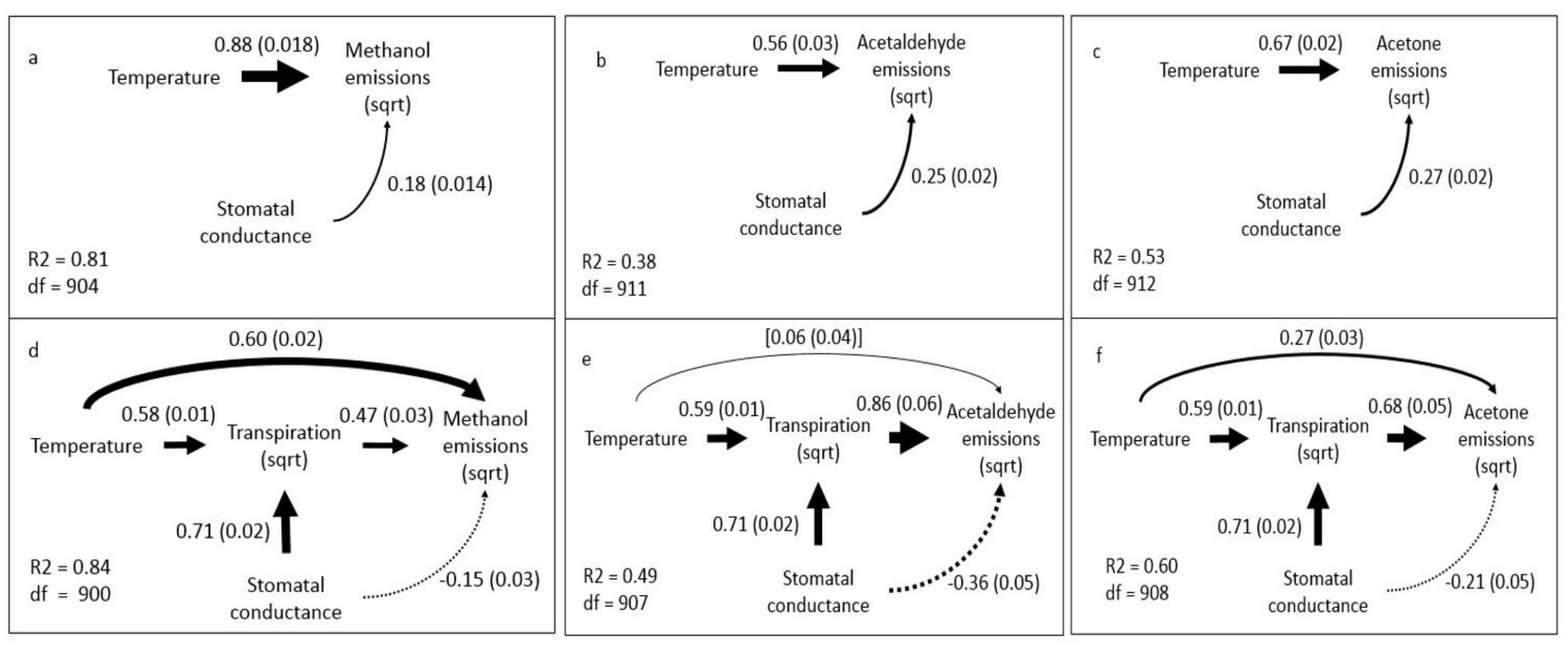

Fig. 6 